\title{
ENHANCED METHOD FOR QUALITY-FIT (ISO 9001) OPERATIONS WITHIN THE AUTOMOTIVE INDUSTRY
}

\author{
Serdal D. Sivri ${ }^{\mathrm{a}}$, Sibylle Hennersdorf ${ }^{\mathrm{b}}$, Hermann Krallmann ${ }^{\mathrm{c}}$ \\ ${ }^{a}$ Technical University of Berlin \& Volkswagen AG, Berlin, Germany \\ ${ }^{b}$ Technical University of Braunschweig (formerly) \& Volkswagen AG, Braunschweig, Germany \\ ${ }^{c}$ Technical University of Berlin (formerly) \& KRALLMANN AG, Berlin, Germany
}

\begin{abstract}
Profit-oriented operations and the delivery of high-quality products are common objectives of business enterprises. The ISO 9001 is the main standard focusing on quality management principles to enable the adherence of these objectives. Its implementation provides an organization with well-defined steering mechanisms for the benefit of an operated quality management system. Nevertheless, many organizations honor the ISO 9001 as a mere obligation to prove the accuracy for a certification. In practice, the processes deviate from those documented and the standard is seen as impractical. The document in hand illustrates how the process-oriented character of the standard is being leveraged as a common dominator to businesses' operations. This character is being used within a project at Volkswagen to embed the specifications of the standard (e.g. measuring and comparing operations, steering documents and recordings) into the organization's process landscape. Systems engineering and tools of process management are illustrated as the enablers within this case. The implementation of the merge between business processes and quality principles results in applied operations in accordance with ISO 9001.
\end{abstract}

Keywords: Quality management principles; ISO 9001; Systems engineering; Business process management; Product change management
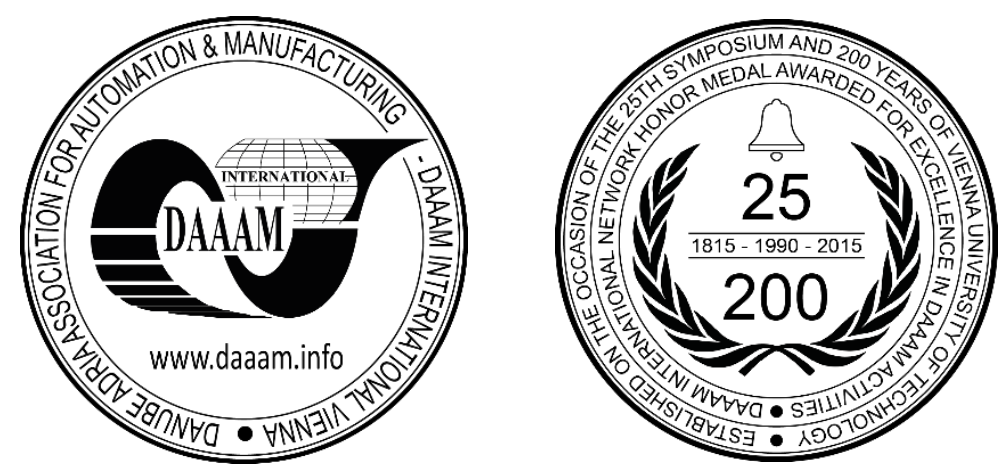

This Publication has to be referred as: Sivri, S[erdal]; Hennersdorf, S[ibylle] \& Krallmann, H[ermann] (2016). Enhanced Method for Quality-fit (ISO 9001) Operations within the Automotive Industry, Proceedings of the 26th DAAAM International Symposium, pp.0614-0619, B. Katalinic (Ed.), Published by DAAAM International, ISBN 9783-902734-07-5, ISSN 1726-9679, Vienna, Austria DOI: $10.2507 / 26$ th.daaam.proceedings.083 


\section{Introduction}

This document in hand contributes to the academic fields of quality management and systems engineering. Moreover, this paper establishes the link between these disciplines. It illustrates how systems engineering can assure the adherence to the specifications of ISO 9001.

The introduction highlights the practical relevance of the work, as well as summarizes existing methods in implementing the ISO 9001.

\subsection{ISO principles as enabler of high quality product changes within the competitive market of the automotive industry}

The automotive industry is faced to tremendous competition. Players tackle constantly for higher market shares. Existing companies try to benefit from their mature competences (e.g. engine, chassis), while emerging ones search for opportunities by developing their core competences around recently upcoming customer trends (e.g. connectivity, online services). The reaction of the manufacturers in launching a variety of new models and variants tightens the situation in the market [1].

An automotive market far away from saturation indicates a retention of this competitive situation. Considering the current motorization rate (amount of vehicles per 1000 people) and its harsh development, the aggressive strategies of new market players and the commitment to high investments seems reasonable. Fig. 1 illustrates the motorization rate. For instance, Asian and South American markets have a significant offset compared to the European market; moreover, they have started their rapid catch-up [2]. In addition, a rise in the total sales volume about by 36 percent within the last 10 years - with a current 87.2 Mio. vehicles per year - highlights the situation as well as the potential of the market and is being recognized by all competitors [3].

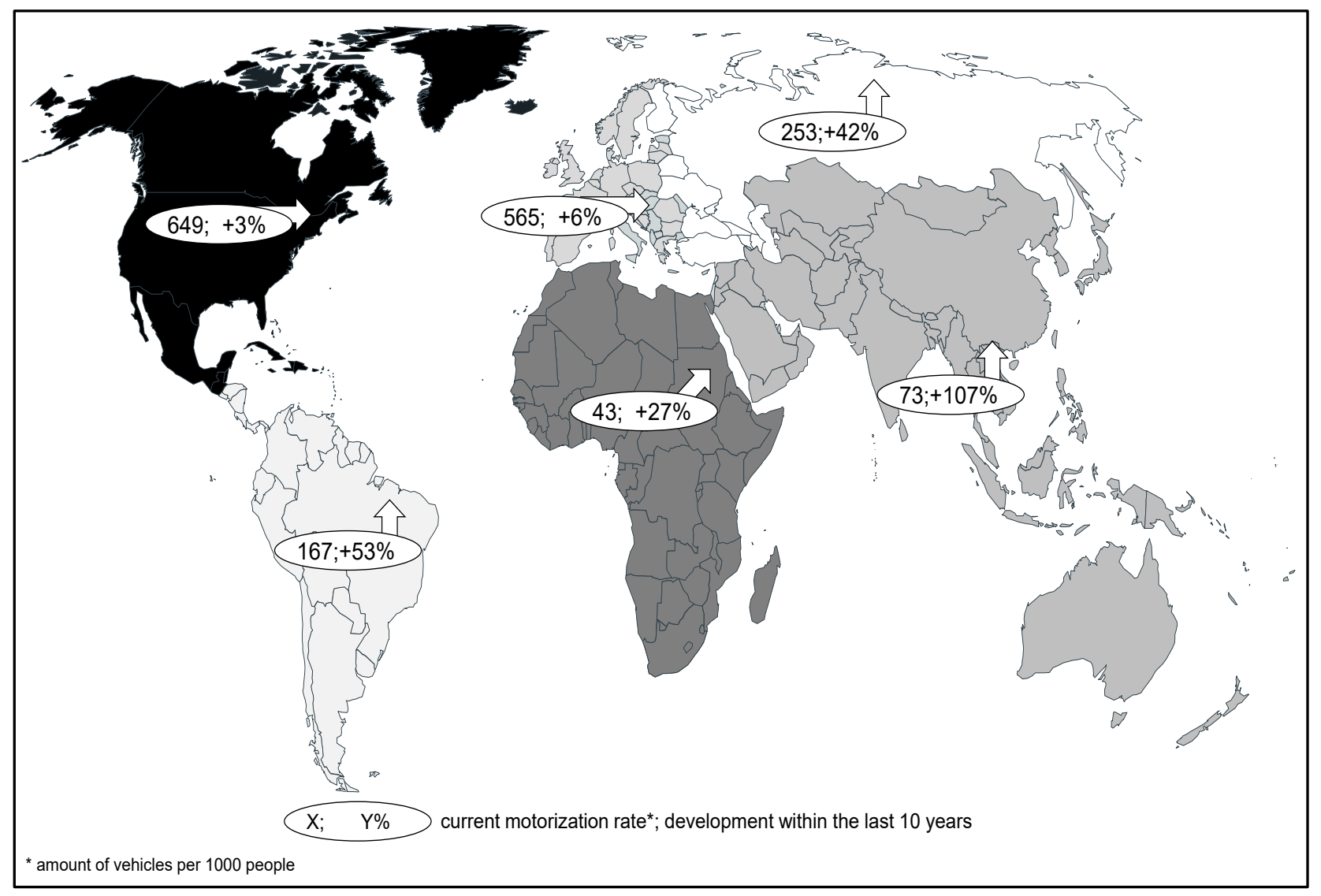

Fig. 1. Motorization rate and its development as indicators of a worthwhile competition

The development of new products clearly acts an important aspect within this competitive situation. While manufacturers are under pressure to adapt emerging new technologies within other industries (e.g. media, environmental services, electronics, telecommunication) into their product, the life cycles significantly differentiate. Whereas the information and telecommunication industry copes with lifecycles from 0.5 to 3 years on average, the automotive industry designs their products for 6 to 10 years [4]. In fact, the automotive industry cannot keep pace with the life cycles and development times of its built-in units based upon diverse other industries. Nevertheless, the attractiveness of the product has to be preserved through the entire lifetime to maintain competitiveness. At Volkswagen, this task is being accepted by the product change management. Regardless of competition and time pressures, the application of product changes 
has to be converted in high quality for the customer and profitability for the organization. The ISO 9001 with its principles copes with these two objectives [5,6,7]. In this context, the standard has been accepted within the product change management at Volkswagen as one crucial enabler to deliver high quality products in a profitable manner.

Many organizations set-up their activities by respecting the ISO 9001. Considerations in detail disclose that processes deviate from those documented. Within a project in the product change management of Volkswagen, this challenge has been identified. The approach within this article illustrates a remedy for this deviation and assures that organizational operations conform to the standard.

\subsection{Academic review on current methods of ISO realization}

The academia addressing the topic of ISO 9001 considers the organizational science more intense, rather than the technical science.

Even later stages such as the implementation are interpreted as the provision of manuals that specify responsibilities, authorities and activities. Corresponding trainings finalize the implementation and enable the organizational members to act in conformity with the standard's principles. [8]

The main topics of this organizational view focus on the motivation, barriers, success factors and benefits of ISO 9001 conform and certified procedures $[9,10,11,12]$. Research highlights that employees' awareness and involvement within the implementation are crucial success factors. Closer examination reveals that perceived benefits from the implementation and ISO certification do not primarily focus on the the sake of employees. Indeed, employees' reduction in workload, work efficiency and motivation are not the main benefits; rather, the complexity of paper work is one of the main shortcomings $[9,12]$.

The paper in hand ensures a beneficial result for each employee through its approach. Furthermore, it agrees about the importance of the organizational view, nevertheless additionally highlighting the technical component.

\section{The enhanced method for the realization of ISO principles}

This part of the document suggests a new approach in realizing the principles of ISO 9001 within an organization. The premise of this approach is to ensure ISO conform processes under the terms that the executed activities do not deviate from the documented and certified ones. Due to the reflection of academic insights, this paper sets two presumptions as the reason for the described deviation in organizations.

- First reason, any motivation and involvement of employees is likely to be minor over the period of ISO realization.

- Second reason, the stage of implementation is increasingly understood as a roll-out of manuals, the transparency of new processes and the supply of corresponding trainings while the technical perspective is neglected.

Therefore, the approach in hand concentrates on alleviating these weaknesses of the classical ISO realization.

The application of systems engineering and tools of BPM (Business Process Management) ensures the interlock between the organizational and technical view. Fig. 2 illustrates the approach in relation to the classical method in realizing ISO conform and certified procedures.

The entire approach is embedded within the model of systems engineering. The sequence of project definition, AS-IS analysis, TO-BE design and implementation aims to translate business objectives into the organization's process landscape $[13,14]$. Each particular stage includes activities of the classical method in ISO certification, as well as activities of business process management. BPM can utilized from the continuum of business process re-engineering up to continues improvement process $[15,16,17,18,19]$. The elaborated and applied approach can be classified as the optimization of business processes, thus situated in the middle of the referred design continuum.

Within the project definition, the mere ISO objectives that focus on product, productivity, customer needs and image are complemented by objectives highlighting the quality of processes and increasing the satisfaction of employees. Accordingly, a staff-oriented setup can be ensured at the beginning of the project.

The AS-IS analysis comprises the activities to understand the ISO principles as well as the evaluation of current operations. Thus, the hitherto ISO-focused stage is enhanced by the view on the relevant business processes and their current state. The ISO principles are analyzed and a coherent understanding of their effect on steering documentations, the responsibility of leadership, the management of resources, product realization and product optimization is elaborated. In addition, relevant business processes are specified and documented. The documentation is conducted by covering the activity, its responsible as well as the system and data in use. This documentation is conform to the holistic consideration within the organization's architecture [20,21,22]. Under the term of this documentation, the identification of process weaknesses can be conducted by the involvement of the employee. Thus, the ongoing project is accepted by the employees as being partly for their direct benefit. 


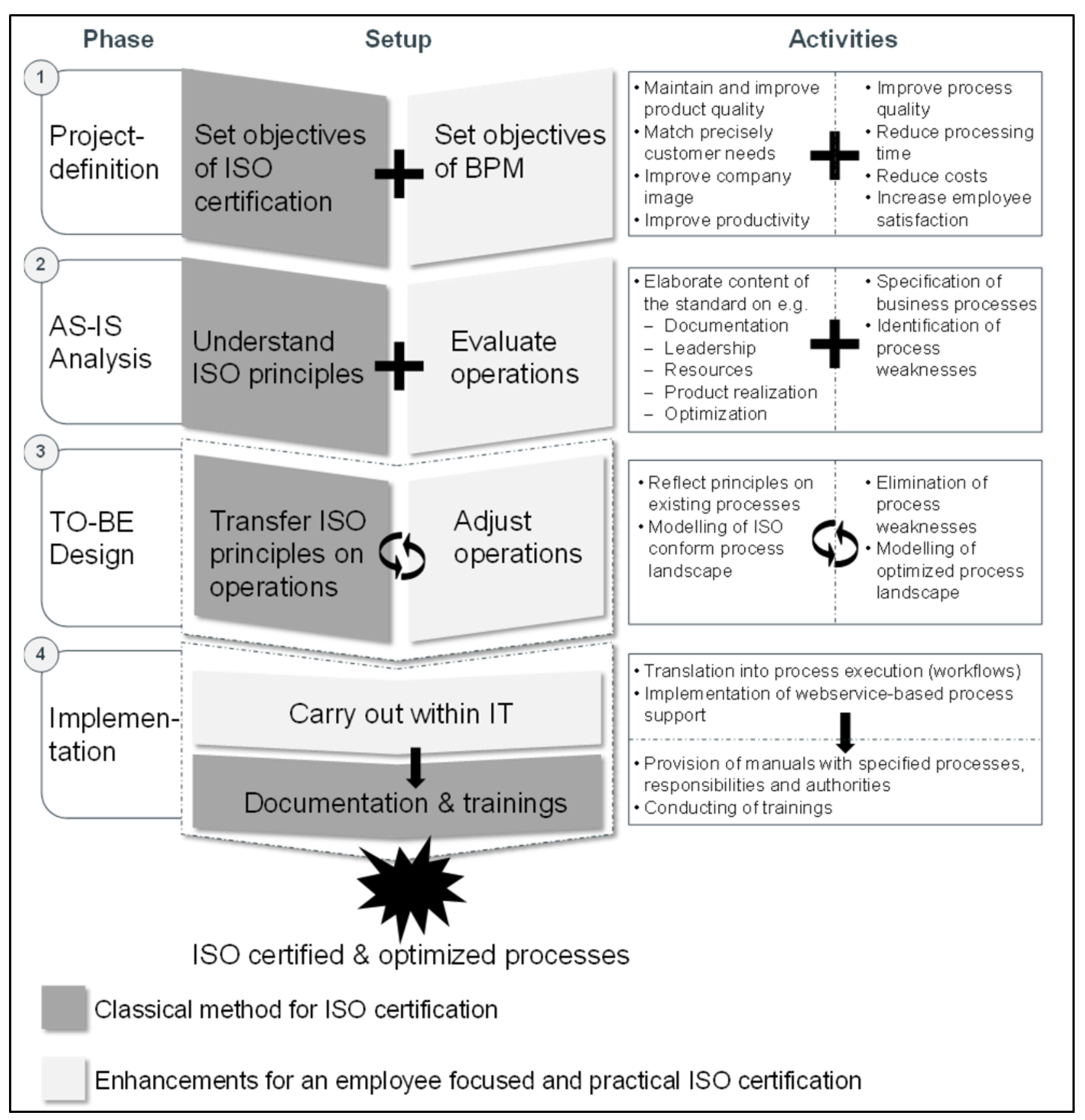

Fig. 2. Enhanced method in realizing ISO 9001 principles

Subsequently, the TO-BE design ensures unison between the ISO principles and optimized operations. The previously elaborated guideline of the ISO principles is reflected on the relevant processes. In addition, the identified process weaknesses are eliminated. The merge between both activities results in ISO conform and optimized concept of the prospective organizational rules and process landscape.

The succession of technological realization and document-based deliveries with suitable trainings constitutes the implementation. The technical view extends the hitherto classical approach, which intensifies the organizational aspects. First, the concept is translated into the IT level by means of specifying the process execution. Moreover, the web servicebased process support is developed based upon the specified execution model [23,24]. Within this technical realization, aspects such as the choice of the application server as well as the workflow engine are substantial. Depending on the degree of integrating existing systems and the variety of deployed technologies, the alternatives have to be evaluated. Thus, the final choice concerning the applied technologies has to be aligned based upon the organization's IT architecture [25]. Second, delivered documents and conducted trainings complete the phase of implementation. These activities originate from the classical method for ISO certification. The provisioned and automated processes are illustrated with their respective responsibilities, authorities and organizational rules within the QM-manual. Corresponding trainings ensure employees' ability to apply the adjusted system. 


\section{Results}

The result of this work is a proposed new method in realizing ISO principles. In detail, it is an enhancement of the classical method in ISO certification. The elaboration of the presented method is based on an academic review.

This review discloses that the motivation and involvement of employees is one major key success factor within ISO projects. Nevertheless, a project focused merely on the ISO certification neglects direct benefits for operativelyinvolved employees. Furthermore, current academia largely focuses on organizational science and neglects the technical perspective; indeed, even the phase of implementation merely highlights the importance of manuals and trainings. These two factors are presented as the reasons of the deviation between organizational operations from certified processes.

As the suggested method is enhanced by objectives focusing the benefits of employee, a high degree of participation is already ensured at the beginning of the project. Besides the project definition, the AS-IS analysis inasmuch as the TO-BE design involves the understanding and active contribution of the employees. The result is a detachment from a mere ISO-focused project progress towards a project with high employee involvement and embedded employee interests.

Within the implementation, mere organizational aspects are extended by technical aspects. The aligned TO-BE design is converted into the IT-level and is executed with workflows. By the reason that the implementation considers the technical view of process execution, the adherence of the designed processes can be ensured.

Consequently, the mentioned two reasons for the described deviation between operations and certified processes can be settled.

- First reason, any motivation and involvement of employees is likely to be minor over the period of ISO realization.

- Second reason, the stage of implementation is increasingly understood as a roll-out of manuals, the transparency of new processes and the supply of corresponding trainings while the technical perspective is neglected.

Therefore, the target of the research to understand the deviation between organization's operations and certified processes as well as to propose a method that eliminates this deviation is presented.

\section{Conclusion \& discussion}

This document and its content explore the deviation between ISO-certified processes and vital operated activities within organizations. The problem is that organizations setup their processes and organizational structures with the aim to be conform to ISO principles. In practice, the operated activities by the employees deviate from the described and certified ones.

The content in hand reviews academia and presumes reasons of this deviation. Based on this review, the classical approach is being understood. In addition, an enhanced method in ISO-certification is being elaborated and proposed. The proposed method and its application are presented as the solution to prevent the mentioned deviation between organizational operations and certified processes. More in detail, the low involvement of employees and the neglect of the technical view are being alleviated by the enhanced approach. The employees are guided by web service-based process support through the aligned processes and the organization operates in conformity with ISO principles without any deviation from designed rules.

The application of the illustrated method has possible consequences on the organization. At strategical level designed processes could ensure objectives as profitability as well as the delivery of high quality products to customer. These are effects of ISO-conform operated processes. At operational level, process weaknesses are expected to be eliminated. Further, as the project involves a high degree of employee's participation, the designed and implemented outcome should be accepted highly by the employee as well as should increase employee satisfaction. As the method is oriented on the adherence of ISO principles, the IT-based implementation could be inadaptable in case of any new revised ISO standard or for any prospective change requests.

Future plans are to apply the proposed method at the product change management at Volkswagen. The evaluation of the concept will be conducted after realizing the practical project at Volkswagen. As within the AS-IS analysis applied activities, consumed times and employee's discomforts have been gathered, these will be compared to the state after application.

Nevertheless, the entire method is elaborated based on a practical project within the department for product change management within the automotive industry. More in detail, the application and evaluation will be accomplished at Volkswagen. Thus, the general effect on organizations is uninvestigated. Future research could proceed to apply the method within other departments of the automotive industry, or even within other automotive manufacturers.

\section{References}

[1] H. Waltl, H. Wildemann, Modularisation within the production of the automotive industry, Modularisierung der Produktion in der Automobilindustrie, first ed., TCW Transfer-Zentrum, München, 2014.

[2] OICA, Vehicles in use. Motorization rate, Organisation Internationale des Constructeurs d'Automobiles, 28.09.2015, online available: http://www.oica.net/category/vehicles-in-use/. 
[3] IHS Automotive, Light Vehicle Sales Forecasts, IHS Automotive 7 (15), 2015, online available: https://www.ihs.com/products/automotive-light-vehicle-sales-forecasts.html.

[4] U. Raubold, Ulrich, Lifecycle management within the automotive industry. An optimization approach based on impact factors of lifecylces, Lebenszyklusmanagement in der Automobilindustrie. Ein Optimierungsansatz auf Basis der auf den Lebenszyklus wirkenden Einflussfaktoren, first ed., Gabler Verlag, Wiesbaden, 2011.

[5] ISO, E. N., 9001: 2008, Quality management systems — Requirements (ISO 9001), 2008

[6] I. Heras-Saizarbitoria, O. Boiral, ISO 9001 and ISO 14001. Towards a Research Agenda on Management System Standards, International Journal of Management Reviews 15 (1), 2013, pp. 47-65.

[7] P. Sampaio, P. Saraiva, A. Gomes, ISO 9001 European Scoreboard: an instrument to measure macroquality, Total Quality Management \& Business Excellence 25 (3-4), 2014, pp. 309-318.

[8] S. Metz-Schimmerl, W. Schima, C. J. Herold, Certification according ISO 9001, Waste of time or necessity?, Zertifizierung nach ISO 9001. Zeitverschwendung oder Notwendigkeit?, Der Radiologe 42 (5), 2002, pp. 380-386.

[9] A. M. S. Al-Rawahi, A. H. Bashir, On the implementation of ISO 9001: 2000: a comparative investigation, The TQM Journal 23 (6), 2011, pp. 673-687.

[10] S. X. Zeng, P. Tian, C. M. Tam, Overcoming barriers to sustainable implementation of the ISO 9001 system, Managerial Auditing Journal 22 (3), 2007, pp. 244-254.

[11] F. Piskar, S. Dolinsek, Implementation of the ISO 9001: from QMS to business model, Industrial Management \& Data Systems 106 (9), 2006, pp. 1333-1343.

[12] J. A. Williams, The impact of motivating factors on implementation of ISO 9001:2000 registration process, Management Research News 27 (1/2), 2004, pp. 74-84.

[13] H. Krallmann, A. Bobrik, O. Levina, Systems engineering in companies. Process-oriented method of business informatics, Systemanalyse im Unternehmen. Prozessorientierte Methoden der Wirtschaftsinformatik, sixth ed., Oldenbourg, München [et al.], 2013.

[14] H. Krallmann, J. Grandt, S. D. Sivri, Digitized processlandscapes. An approach for sustainable knowledge management within the automotive industry, Digitalisierte Prozesslandschaften. Ein Ansatz zum nachhaltigen Wissensmanagement in der Automobilindustrie, Wissensmanagement - Das Magazin für Führungskräfte (7/15), 2015, pp. 14-17.

[15] M. Dumas, Fundamentals of business process management, Springer, Berlin, New York, 2013.

[16] V. Grover, M. K. Malhotra, Business process reengineering. A tutorial on the concept, evolution, method, technology and application, Journal of Operations Management 15 (3), 1997, pp. 193-213.

[17] M. Hammer, J. Champy, Reengineering the corporation. A manifesto for business revolution, Harper Business Essentials, New York, 2003.

[18] M. Brenner, J. Paulus, Methods in increasing process performance, Ansätze zur Steigerung der Prozessperformance, Prozessmanagement umsetzen, Stuttgart, 2005, pp. 7-16.

[19] N. Stefanic, N. Toskanovic, S. Martincevic-Mikic. Improvement of production by using Kaizen, in B. Katalinic (Eds.), Annals of DAAAM \& Proceedings, 2009, pp. 1365-1366.

[20] A.-W. Scheer, Architecture of integrated information systems. Basics of corporate modeling, Architektur integrierter Informationssysteme. Grundlagen der Unternehmensmodellierung, Springer, Berlin, New York, 1991.

[21] G. Keller, M. Nüttgens, A.-W. Scheer, Semantic process modeling based on 'event-driven process chains (EPC)', Semantische Prozessmodellierung auf der Grundlage "Ereignisgesteuerter Prozessketten (EPK)", in: A.-W. Scheer (Eds.), Veröffentlichungen der Instituts für Wirtschaftsinformatik (89), Universität des Saarlandes, Institut für Wirtschaftsinformatik (IWi), Saarbrücken, 1992.

[22] A.-W. Scheer, O. Thomas, O. Adam. Process modeling using event-driven process chains, in: M. Dumas, W. van der Aalst, A. Ter Hofstede (Eds.): Process-aware information systems. Bridging people and software through process technology. Wiley-Interscience, Hoboken, New Jersey, 2005, pp. 119-146.

[23] S. D. Sivri, H. Krallmann, Process-oriented Knowledge Management within the Product Change Systems of the Automotive Industry, in: B. Katalinic (Eds.), 25th DAAAM International Symposium on Intelligent Manufacturing and Automation, Procedia Engineering 100, 2015, pp. 1032-1039.

[24] P. Hens, M. Snoeck, G. Poels, M. Backer, Process fragmentation, distribution and execution using an event-based interaction scheme, The Journal of Systems and Software 89, 2014, pp. 170-192.

[25] M. Kaib, Enterprise application integration. Fundamentals, integration products, use cases, Enterprise Application Integration. Grundlagen, Integrationsprodukte, Anwendungsbeispiele, Deutscher Universitätsverlag, Wiesbaden, 2002 . 